\title{
Correction to: A computationally efficient and scalable key management scheme for access control of media delivery in digital Pay-TV systems
}

\author{
Vinod Kumar $^{1} \cdot$ Rajendra Kumar $^{2}$ - S. K. Pandey ${ }^{3}$ \\ Published online: 10 October 2020 \\ (C) Springer Science+Business Media, LLC, part of Springer Nature 2020
}

\section{Correction to: Multimedia Tools and Applications (2019) \\ https://doi.org/10.1007/s11042-020-08904-8}

Tables $1,3,4,5,6,7,8$ and the body texts in the original publication contain incorrect symbols. The original article article has been corrected.

Publisher's note Springer Nature remains neutral with regard to jurisdictional claims in published maps and institutional affiliations.

The online version of the original article can be found at https://doi.org/10.1007/s11042-020-08904-8

\section{Vinod Kumar}

vk@allduniv.ac.in

1 Department of Electronics and Communication (Computer Science \& Engineering), University of Allahabad, Allahabad, UP, India

2 Department of Computer Science, Jamia Millia Islamia, New Delhi, India

3 Division of e-Governance, Ministry of Electronics \& Information Technology (Government of India), New Delhi, India 